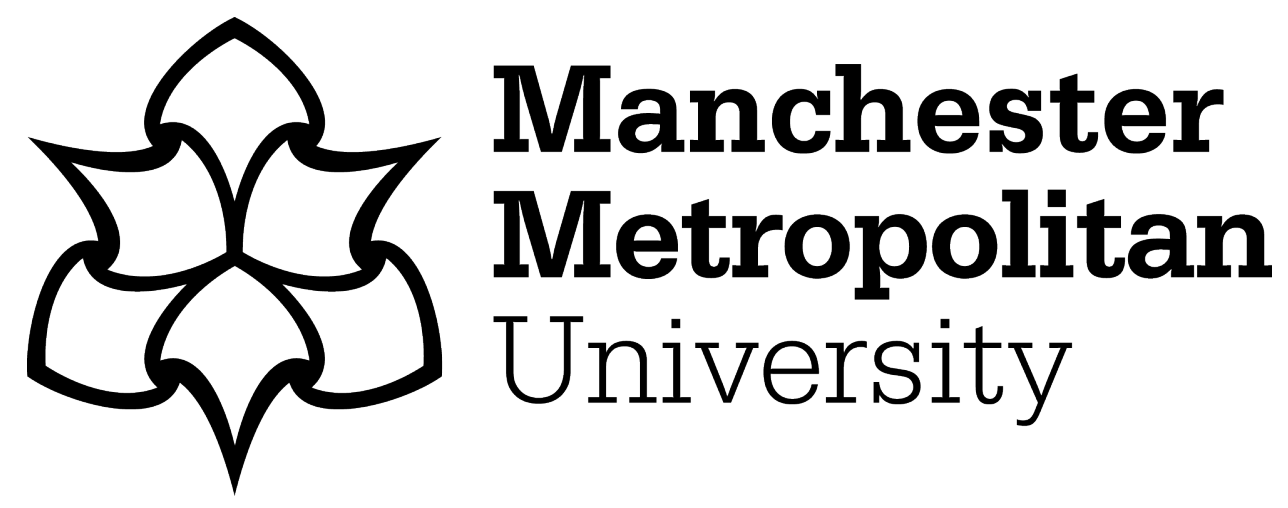

Karamanlioglu, M, Preziosi, R and Robson, GD (2017) The Compostable Plastic Poly(lactic) Acid Causes a Temporal Shift in Fungal Communities in Maturing Compost. Compost Science and Utilization, 25 (4). pp. 211-219. ISSN 1065-657X

Downloaded from: https://e-space.mmu.ac.uk/619674/

Version: Accepted Version

Publisher: Taylor \& Francis

DOI: https://doi.org/10.1080/1065657X.2016.1277808

Please cite the published version 


\title{
The Compostable Plastic Poly(lactic) Acid Causes a Temporal Shift in Fungal Communities in Maturing Compost
}

\author{
Mehlika Karamanlioglua ${ }^{\mathrm{a}}$, Richard Preziosi ${ }^{\mathrm{b}}$, and Geoffrey D. Robson ${ }^{\mathrm{a}}$ \\ ${ }^{a}$ School of Biological Sciences, University of Manchester, Manchester, UK; ${ }^{b}$ Division of Biology and Conservation Ecology, School of Science \\ and the Environment, Faculty of Science and Engineering, Manchester Metropolitan University, Manchester, UK
}

\begin{abstract}
The compostable biopolymer, poly(lactic) acid (PLA), is increasingly being used as an alternative to conventional plastics for short shelf-life products, disposable bags and packaging, and in agriculture. Despite the increase in the amount of PLA entering composting systems, few studies have examined the impact of PLA degradation on the compost microbial community. Thermophilic fungi play an import role in the composting process as they secrete hydrolytic enzymes capable of breaking down an array of complex natural polymers. In this study, the impact of PLA hydrolysis on the compost fungal community was examined by terminal restriction fragment length polymorphism and 454 sequencing. At $25^{\circ} \mathrm{C}$, the effect of PLA on the surrounding compost community was relatively small and no physical changes were observed to the PLA films. However, when incubated at $50^{\circ} \mathrm{C}$, where physical disintegration of PLA was occurring, a clear divergence between the compost populations in the presence and absence of PLA was evident after 2 months but became closer to the population in the absence of PLA after 4 months indicating that, after causing an initial perturbation after 2 months, the population began to return to that seen in the absence of PLA. The only exception was in the population containing 50\% (w/w) PLA film, which remained divergent after 4 months and was associated with a marked acidification of the compost. Thus, 454-pyrosequencing revealed that the presence of PLA caused a strong selection for a Thermomyces sp. that was present only at low abundance in the absence of PLA.
\end{abstract}

\section{Introduction}

Worldwide plastic production reached 311 million tons in 2014 (Plastics Europe 2016), with packaging accounting for the largest market sector (39\%). Currently, plastics used for this sector are largely comprised of synthetic petroleum-based polymers including polyethylenepolypropylene, polyvinyl chloride, polystyrene, and polyethylene terephthalate, which are poorly degraded in the environment (Sabev et al. 2006; Shah et al. 2008; Shimao 2001; Sivan 2011).

Poly(lactic acid) (PLA) is a synthetic compostable biopolymer with a hydrolysable backbone that degrades at elevated temperatures abiotically releasing lactic acid (Bohlmann 2005; Drumright et al. 2000; Garlotta 2002; Lim et al. 2008; Williams 1982). PLA has favorable mechanical qualities comparable to petrochemical-based non-biodegradable (Auras et al. 2003; Lunt 1998). Global PLA production reached 180,000 tons in 2011 and is estimated to reach at least 800,000 tons p.a. by 2020 with the majority used for packaging (Nova Institute 2016). As global production of PLA is increasing with its main application being short-shelf-life compostable products, it is important to understand its impact on compost communities. Ghorpade et al. (2001) reported that PLA could efficiently be composted when added in amounts lower than $30 \%(\mathrm{w} / \mathrm{w})$ as lactic acid released through hydrolysis at higher levels of suppressed microbial growth. However, the impact of PLA degradation on microbial diversity was not assessed (Ghoparde et al. 2001). Sangwan and $\mathrm{Wu}$ (2008) and Sangwan et al. (2009) used clone libraries to identify putative PLA degraders from the surface of PLA; we have previously shown that degradation at elevated temperatures is accelerated by the presence of microbes and that compost contains thermophilic fungi capable of degrading PLA (Karamanlioglu and Robson 2013; 
Karamanlioglu et al. 2014). However, none of these studies have investigated the impact of PLA degradation on the surrounding microbial community, which may impact on commercial composting.

\section{Materials and Methods}

\section{Polylactic Acid (PLA)}

PLA films (Mw 160,000 $\pm 6000 \mathrm{~g} / \mathrm{mol}$, determined by gel permeation chromatography, results not shown) were cut from PLA food containers produced from semi-crystalline PLA (Ingeo $^{\text {TM }}$ Biopolymer, Grade 2003D, 96\% L-isomer; obtained from NatureWorks LLC, USA and distributed through VegWare, Edinburgh, UK). According to the supplier, PLA resins contained $96 \%$ L-lactic acid isomer, a density of $1.24 \mathrm{~g} / \mathrm{cm}^{3}$, melting temperature of $145^{\circ} \mathrm{C}-170^{\circ} \mathrm{C}$, glass transition temperature of $55^{\circ} \mathrm{C}-58^{\circ} \mathrm{C}$, and $35 \%$ crystallinity.

\section{Compost Source}

Commercial compost in its cooling phase (average temperature $44^{\circ} \mathrm{C}$ ) was purchased from The Compost Shop, UK. Compost had been screened to $10 \mathrm{~mm}$ to eliminate large particles but no further commercial pre-treatments were applied to the compost. Compost was sieved through a $2-\mathrm{mm}$ mesh to remove particles $>2 \mathrm{~mm}$ after purchase and stored at room temperature. Water holding capacity was determined to be $60 \%-64 \%$ by a modified method of Forster (1995) and the moisture content was adjusted to $30 \%-32 \%$ by adding sterile water through a plant spray prior to use.

\section{PLA Amended Compost}

PLA squares $(1 \times 1 \times 0.02 \mathrm{~cm})$ were cut from delicatessen containers and surface sterilized with $70 \%(\mathrm{v} / \mathrm{v})$ ethanol. Sterility was checked by incubating PLA films on potato dextrose agar (PDA) and Luria-Bertani (LB) plates. PLA squares were mixed with compost to give $0,10,25$, and $50 \%(\mathrm{w} / \mathrm{w})$ PLA in rectangular plastic boxes $(3 \mathrm{~L})$ to give a final depth of ca. $7 \mathrm{~cm}$ and incubated at 25 and $50^{\circ} \mathrm{C}$. Boxes were weighed periodically and water loss adjusted by the addition of sterile water using a plant spray.

\section{pH Determination}

The $\mathrm{pH}$ of compost was determined after mixing compost samples with distilled water (ratio 1:2) and standing for $1 \mathrm{~h}$ according to Forster (1995) and the $\mathrm{pH}$ of supernatant was measured with a $\mathrm{pH}$ meter (Metler Toledo, UK).

\section{DNA Extraction from Compost}

Total DNA from compost $(0.25 \mathrm{~g})$ and from PLA amended compost (excluding PLA film) were extracted using a Power Soil DNA extraction kit (Mo Bio Laboratories, UK) according to the manufacturer's instructions and quantified using a Nanodrop 1000 (Thermo Fisher Scientific, UK). For each compost sample, DNA was extracted from three replicates and DNA stored at $-20^{\circ} \mathrm{C}$ in $10 \mathrm{mM}$ Tris buffer $(\mathrm{pH} 8)$ until required.

\section{Terminal Restriction Fragment Length Polymorphism (TRFLP) Analysis of Fungal Communities}

Fungal community profiles in compost were analyzed by TRFLP as previously described (Karamanlioglu et al. 2014; Kawasaki et al. 2012). Fluorescently labeled fragments were separated and detected in-house by capillary electrophoresis (ABI Prism ${ }^{\circledR} 3100$ Genetic Analyzer, Applied Biosystems Inc., Foster City, USA). The size of detected terminal restriction fragments (TRFs) was assessed by comparison with an internal size standard using Peak Scanner ${ }^{\mathrm{TM}}$ software (Applied Biosystems, California, USA), and aligned using the T-align program (T-align 2016).

T-align initially compared the replicate profiles within one sample and displayed TRFs with their abundance (peak area) after eliminating pseudo peaks (Smith et al. 2005). A single consensus profile was generated from the three replicates and TRFs displayed with their average peak areas and then normalized so that each peak area corresponded to the percentage of the total fluorescence (Smith et al. 2005).

Principal component analysis (PCA) was used to compare TRF profiles in the fungal communities and diversity index $\left(\mathrm{H}^{\prime}\right)$ and evenness values ( $\mathrm{J}^{\prime}$; Atlas and Bartha, 1986) were calculated using MVSP software (Ver. 3.12d, Kovach Computing Services).

\section{4-Pyrosequencing}

454-Pyrosequencing was used to identify the dominant fungal taxa in compost samples. 454-Pyrosequencing was conducted by MR DNA (Shallowater, TX, USA) 
by amplicon pyrosequencing (bTEFAP) as described by Dowd et al. (2008). Total DNA concentration was adjusted to $30-40 \mathrm{ng} / \mu \mathrm{l}$ and subjected to initial polymerase chain reaction (PCR) using ITS5 (GGAAGTAAAAGTCGTAACAAGG) and ITS4 (TCCTCCGCTTATTGATATGC; White et al. 1990) primers to amplify the ITS1-5.8S-ITS2 region of fungal rRNA genome using a HotStarTaq Plus Master Mix Kit (Qiagen, Valencia, CA, USA). Cycling conditions were as follows: Initial denaturation at $94^{\circ} \mathrm{C}$ for $10 \mathrm{~min}, 35$ cycles of denaturation at $94^{\circ} \mathrm{C}$ for $1 \mathrm{~min}$, annealing at $54^{\circ} \mathrm{C}$ for $1 \mathrm{~min}$, extension at $72^{\circ} \mathrm{C}$ for $1 \mathrm{~min}$, and final extension at $72^{\circ} \mathrm{C}$ for $10 \mathrm{~min}$. Amplicons were adjusted to equal concentrations and purified using Agencourt Ampure beads (Agencourt Bioscience Corporation, MA, USA) according to the manufacturers protocol and subjected to pyrosequencing using a Roche 454 FLX Titanium Instrument following the manufacturer's instructions (MR DNA Lab, Shallowater, TX, USA). The average number of reads per assay was ca. 3000 and analyzed using the QIIME pipeline (Caporaso et al. 2010). Primers, barcodes, and short sequences
$<200$ bp was removed and split libraries formed. Sequences were clustered at $97 \%$ similarity and assigned to operational taxonomic units (OTUs) using QIIME with UNITE + NCBI Genbank database according to instructions given on the QIIME website for fungal ITS analysis (QIIME 2016).

\section{Results}

\section{Visual Changes to PLA Films During Incubation in Compost}

To determine any physical changes to the PLA films during incubation in compost at 25 or $50^{\circ} \mathrm{C}$, samples were removed periodically and visually compared with controls (not incubated with compost). When the PLA films were incubated with compost at $25^{\circ} \mathrm{C}$, there were no visible signs of degradation or other physical changes in appearance and appeared identical to control films (figures $1 A$ and $1 B$ ). However, films incubated in compost at $50^{\circ} \mathrm{C}$ became opaque and showed physical signs of disintegration after 2 months (figure $1 C$ ) and was no longer visible after 4 months.
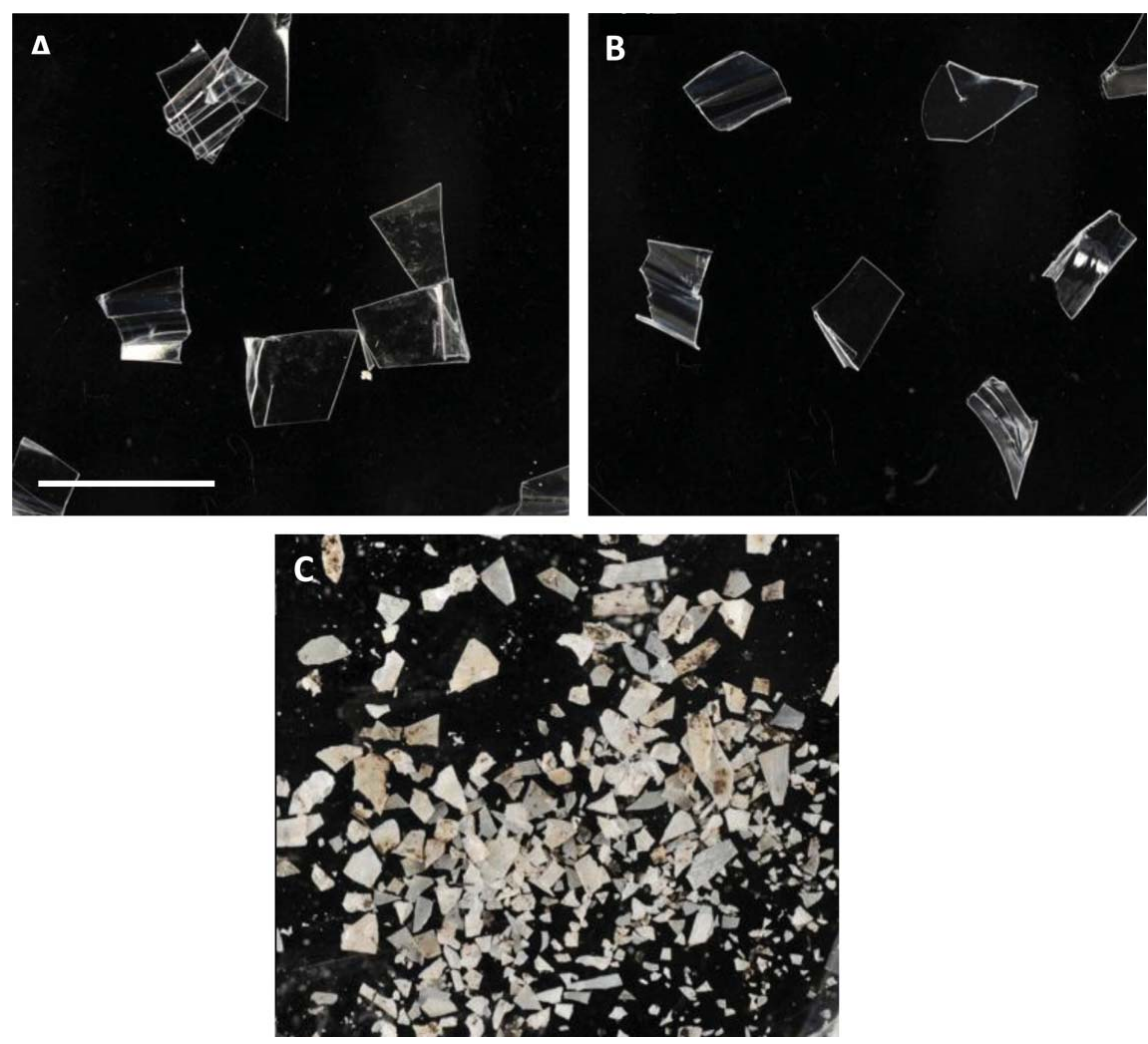

Figure 1. Physical changes in PLA films buried in compost. PLA films were mixed with compost and incubated at 25 and $50^{\circ} \mathrm{C}$ for up to 4 months. $A$, Films before incubation with compost. $B$, Films after 2 months incubation with compost at $25^{\circ} \mathrm{C}$. $C$, Films after 4 months incubation with compost at $50^{\circ} \mathrm{C}$. Scale bar represents $1 \mathrm{~cm}$. 


\section{Effect of PLA on Compost pH}

As PLA hydrolysis ultimately leads to the generation of its monomer, lactic acid, the $\mathrm{pH}$ of compost containing $0,10,25$, and $50 \%(\mathrm{w} / \mathrm{w})$ PLA films incubated at 25 or $50^{\circ} \mathrm{C}$ were measured before and after 2 and 4 months incubation. The initial compost had a pH of $7.1 \pm 0.2$ and no significant $(p>0.05)$ change was observed after 2 or 4 months incubation at $25^{\circ} \mathrm{C}$ with PLA films. Similarly, at $50^{\circ} \mathrm{C}$, no significant $(p>0.05)$ change in $\mathrm{pH}$ was observed in compost in the presence of films with the exception of $50 \%$ (w/w) PLA films where the $\mathrm{pH}$ decreased to $3.3 \pm 0.1$ after 4 months (data not shown).

\section{Influence of PLA on the Fungal Compost Community over 4 months}

In order to determine the influence of PLA on the fungal compost community, compost samples were removed after 0,2 , and 4 months; total DNA was extracted and subjected to TRFLP analysis. TRF profiles from compost incubated at 25 and $50^{\circ} \mathrm{C}$ containing $0,10,25$, and $50 \%(\mathrm{w} / \mathrm{w})$ PLA films were subjected to principle component analysis (PCA) following normalization (figures $2 A$ and $2 B$ ). Consequently, $50^{\circ} \mathrm{C}$ was chosen to represent the initial cooling phase when fungi first become dominant in the compost, and $25^{\circ} \mathrm{C}$ was chosen to represent the mature phase after cooling.

When PLA films were incubated in compost at $25^{\circ} \mathrm{C}$, two principal components (PC1 and $\mathrm{PC} 2$ ) accounted for $48 \%$ of the total variability in the data set (figure 2A). The first cluster accounted for the compost community prior to incubation and after 2 months at $25^{\circ} \mathrm{C}$ without PLA; the second cluster accounted for the compost community in the presence of $10 \%-50 \%(\mathrm{w} / \mathrm{w})$ PLA incubated for 2 months and 0 and $10 \%$ of PLA after 4 months; and the third cluster accounted for the community in the presence of 25 and $50 \%(\mathrm{w} / \mathrm{w})$ PLA films incubated for 4 months at $25^{\circ} \mathrm{C}$. PC1 mainly showed the difference between 25 and $50 \%(\mathrm{w} / \mathrm{w})$ PLA film-containing compost incubated for 4 months at $25^{\circ} \mathrm{C}$ and the initial compost. PC2 explained $22 \%$ of the variation and showed the difference between compost samples containing 10\%$50 \%$ PLA films incubated for 2 months from the other compost samples. PLA concentration effect was mainly observed after 2 months as compost with PLA grouped away from compost in the absence of PLA.
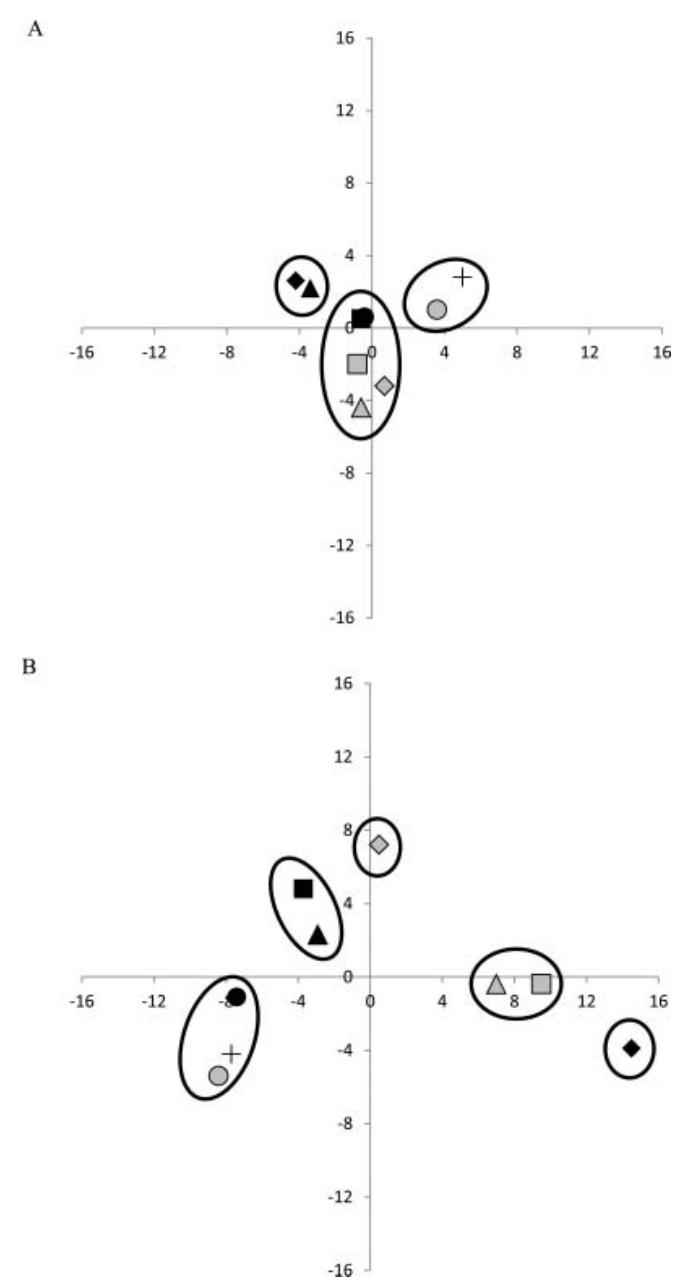

Figure 2. Principal component analysis (PCA) of TRFLP profiles of fungal communities isolated from initial compost $(+)$ and compost after 2 months (grey symbols) and 4 months (black symbols) in the absence $(O, O$ ) or presence of $10 \%(\square, \square), 25 \%$ $(\triangle, \Delta)$ or $50 \%(\triangle,>)$ (w/w) PLA incubated at either $(A)$ $25^{\circ} \mathrm{C}$ or $(B) 50^{\circ} \mathrm{C}$.

When PLA films were incubated at $50^{\circ} \mathrm{C}$, the first two principal components (PC1 and PC2) accounted for $88 \%$ of the total variability in the fungal community (figure $2 B$ ). PC1 accounted for $70 \%$ of the variation and four groups were observed. The first was the initial compost community and compost incubated for 2 and 4 months in the absence of PLA; the second group consisted of compost containing 10 and 25\% PLA films incubated for 4 months and compost containing 50\% PLA incubated for 2 months; the third group contained the profiles for compost containing 10 and 25\% PLA incubated for 2 months; and the final group contained only compost containing 50\% PLA films incubated for 4 months. Changes in the fungal community due to PLA concentration were most apparent after 2 months incubation as all compost 
Table 1. Diversity index $\left(\mathrm{H}^{\prime}\right)$, evenness $\left(\mathrm{J}^{\prime}\right)$, number of TRFs of fungal communities in compost and $\%$ of TRFs only found in PLA film and/or PLA granule containing compost with respect to PLA concentration in compost ( $0 \%-50 \%)$.

\begin{tabular}{|c|c|c|c|c|c|c|}
\hline & & $\begin{array}{l}\text { PLA concentration } \\
0 \% \text {, Initial compost }\end{array}$ & $\begin{array}{c}\text { Shannon diversity }\left(\mathrm{H}^{\prime}\right) \\
3.6\end{array}$ & $\begin{array}{c}\text { Evenness }\left(\mathrm{J}^{\prime}\right) \\
0.7\end{array}$ & $\begin{array}{c}\text { Number of TRFs } \\
145\end{array}$ & $\begin{array}{c}\% \text { of PLA unique TRFs } \\
\text { N/A }\end{array}$ \\
\hline \multirow{8}{*}{$25^{\circ} \mathrm{C}$, compost and PLA films } & 2 months & $0 \%$ & 3.0 & 0.6 & 131 & \\
\hline & & $10 \%$ & 3.4 & 0.7 & 154 & 8 \\
\hline & & $25 \%$ & 3.0 & 0.6 & 152 & 17 \\
\hline & & $50 \%$ & 3.3 & 0.7 & 98 & 4 \\
\hline & 4 months & $0 \%$ & 3.4 & 0.7 & 149 & \\
\hline & & $10 \%$ & 3.6 & 0.7 & 169 & 7 \\
\hline & & $25 \%$ & 3.8 & 0.7 & 192 & 11 \\
\hline & & $50 \%$ & 3.8 & 0.7 & 207 & 14 \\
\hline \multirow[t]{8}{*}{$50^{\circ} \mathrm{C}$, compost and PLA films } & 2 months & $0 \%$ & 3.2 & 0.7 & 84 & \\
\hline & & $10 \%$ & 2.6 & 0.6 & 97 & 16 \\
\hline & & $25 \%$ & 2.7 & 0.5 & 129 & 21 \\
\hline & & $50 \%$ & 2.6 & 0.6 & 52 & 8 \\
\hline & 4 months & $0 \%$ & 3.7 & 0.8 & 137 & \\
\hline & & $10 \%$ & 3.4 & 0.7 & 148 & 26 \\
\hline & & $25 \%$ & 3.5 & 0.7 & 167 & 30 \\
\hline & & $50 \%$ & 1.9 & 0.4 & 86 & 3 \\
\hline
\end{tabular}

Note. Each compost sample had three replicates, which were pooled after PCR, and two technical replicates were aligned to represent each compost sample.

communities containing PLA clustered away from compost in the absence of PLA and the initial compost community. After 4 months incubation, with the exception of $50 \%(\mathrm{w} / \mathrm{w})$ PLA film, populations were closer to the initial compost community and compost incubated in the absence of PLA for 4 months.

The effect of PLA concentrations on diversity of fungal communities in compost was assessed by calculating the number of TRFs, Shannon index $\left(\mathrm{H}^{\prime}\right)$, and evenness values $\left(J^{\prime}\right)$ corresponding to population size, diversity, and evenness of populations in each compost community, respectively (table 1 ).

The number of TRFs in compost containing PLA films $(10 \%-50 \% \mathrm{w} / \mathrm{w})$ incubated at $25^{\circ} \mathrm{C}(\approx 154)$ were mostly similar with the initial compost (145) and compost in the absence of PLA (131) except with a decrease in compost with 50\% PLA films; however, on the 4th month the number of TRFs was similar regardless of PLA concentration. The diversity and the evenness values were high $\left(\mathrm{H}^{\prime}=3.0-3.8 ; \mathrm{J}^{\prime}=\right.$ $0.6-0.7$, respectively) and similar for 4 months with the compost in the absence of PLA. On the 4th month of incubation the number of TRFs, diversity, and evenness increased compared to the 2nd month regardless of the PLA concentrations.

When PLA films were incubated at $50^{\circ} \mathrm{C}$, a drastic decrease in TRF number was observed at $50 \%$ concentration, as the number of TRFs (52) was less than all the other compost samples in the presence and absence of PLA on the 2nd month (84-129). Diversity index decreased $(\mathrm{H} \approx 2.6)$ in compost with $10 \%-50 \%$
PLA films compared to initial $\left(\mathrm{H}^{\prime}=3.6\right)$ and compost with $0 \%$ PLA films $\left(\mathrm{H}^{\prime}=3.2\right)$; however, the sizes of populations in the communities were similar $\left(\mathrm{J}^{\prime} \approx\right.$ $0.6)$ with initial compost and compost with no PLA $\left(\mathrm{J}^{\prime}=0.7\right)$ incubated at $50^{\circ} \mathrm{C}$ for 2 months. The same trend was also observed on the 4th month of incubation; at 50\% PLA film concentration in compost, the number of TRFs decreased drastically (86) compared to $0 \%-25 \%$ PLA containing compost samples (137-167). In addition, fungal diversity $\left(\mathrm{H}^{\prime}=1.9\right)$ and evenness $\left(\mathrm{J}^{\prime}=0.4\right)$ were less than compost having 0\%-25\% PLA $\left(\mathrm{H}^{\prime}=3.4-3.7 ; \mathrm{J}^{\prime}=0.7-0.8\right)$, which had higher diversity and less variation of population sizes in the communities.

\section{Meta-barcoding Analysis}

In order to identify which fungal taxa in the compost community was affected by the degradation of PLA, meta-barcoding analysis was conducted on compost samples incubated at $50^{\circ} \mathrm{C}$ for 2 and 4 months in the presence and absence of $25 \%$ (w/w) PLA films (figure 3). A total of 5557 sequence counts (reads) were obtained with a saturation of $>97 \%$ indicating the major components of the fungal community had been captured. The initial compost kept at $25^{\circ} \mathrm{C}$ had more OTUs than the rest of the samples and contained OTUs from 2 phyla: Ascomycota and Zygomycota (figure 3). The most dominant fungal group in the initial compost sample (50\% relative abundance) was unidentified but belonged to phylum Ascomycota, while the second most abundant (32\% relative abundance) belonged to Ascomycota, 


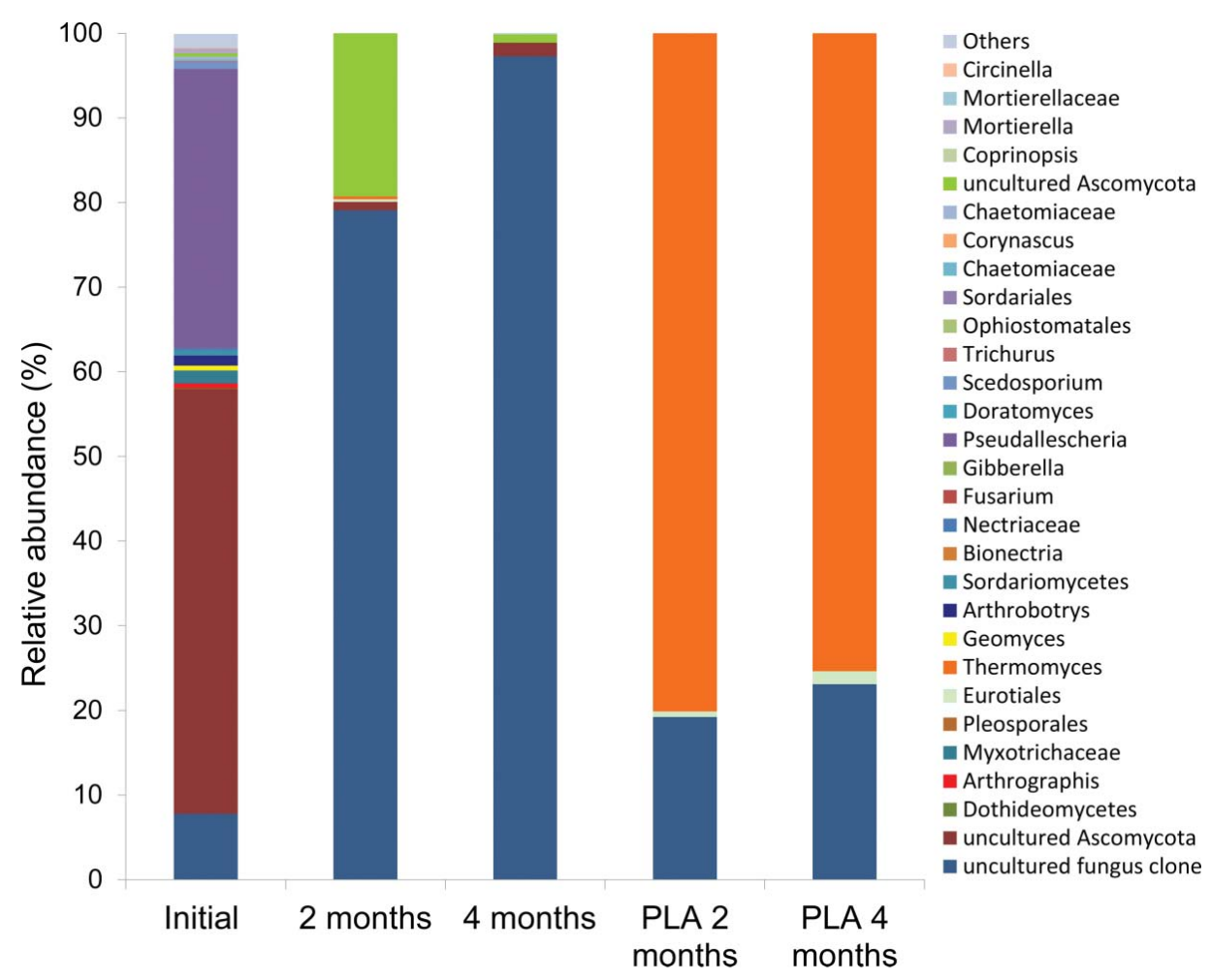

Figure 3. Relative abundance of fungal groups identified by meta-barcoding analysis from compost in the absence and presence of $25 \%$ (v/v) PLA films incubated at $50^{\circ} \mathrm{C}$ for 2 and 4 months. ${ }^{*}$ Indicates molecular operational taxonomic units (mOTUs) unidentified beyond genus level.

Microascaceae, and genus Pseudallescheria. OTUs with low relative abundances were from the phylum Zygomycota (Mortierellaceae; genus Mortierella and Mucoraceae; genus Circinella). An uncultured fungal species, initially present with a relative abundance of $8 \%$ became the dominant species in the absence of PLA after 2 and 4 months incubation (79 and 97\%, relative abundance, respectively) but had a lower abundance in the presence of PLA (18 and 23\% relative abundance after 2 and 4 months incubation, respectively). In the presence of PLA, the dominant fungal group was identified as belonging to the genus Thermomyces (order Eurotiales) with a relative abundance of 80 and $75 \%$ after 2 and 4 months incubation, respectively. This clone was not detected in the original compost and found only after 2 months incubation in the absence of PLA at very low relative abundance $(0.03 \%)$. PLA therefore significantly changed the dominant fungal species present in compost as detected by 454 -pyrosequencing.

\section{Discussion}

PLA is a compostable plastic that is increasingly used commercially as an alternative packaging material for short-shelf-life products. Despite its growing use, few studies have investigated the impact of this material on the compost community and, in particular, on the fungal community. In this study, we investigated the influence of PLA degradation at 25 and $50^{\circ} \mathrm{C}$ on the fungal community using TRFLP. At $25^{\circ} \mathrm{C}$, no visible sign of degradation of PLA films was evident; however, physical fragmentation and degradation were clearly seen when incubated in compost at $50^{\circ} \mathrm{C}$ after 2 months (figure 1) and was completely degraded by 4 months. PLA degradation is known to occur at temperatures close to its glass transition temperature $(\mathrm{Tg}$, $55^{\circ} \mathrm{C}-62^{\circ} \mathrm{C}$ ) in humid environments (Henton et al. 2005; Itävaara et al. 2002; Kale et al. 2007; Saadi et al. 2012; Weir et al. 2004). Polymer chains of PLA soften and become more flexible, which increases water absorption accelerating hydrolysis and microbial attachment (Agrawal et al. 1997; Henton et al. 2005; Kale et al. 2007; Sangwan and Wu, 2008; Vargas et al. 2009).

At $50^{\circ} \mathrm{C}$, PLA films degraded rapidly and were disintegrated by 2 months. Hydrolysis of PLA leads to a progressive decrease in polymer chain length and ultimately the release of soluble oligomers and lactic acid 
causing a decrease in the surrounding $\mathrm{pH}$ (Agarwal et al. 1998; Torres et al. 1996a). In this study, no change in the $\mathrm{pH}$ of compost was observed at $25^{\circ} \mathrm{C}$ confirming the lack of physical degradation observed at this temperature (figure 1). Tensile strength loss was also reported to be insignificant with PLA films even after a year when buried in compost, soil, or immersed in water at $25^{\circ} \mathrm{C}$ (Karamanlioglu et al. 2014). No change in $\mathrm{pH}$ was also observed in compost incubated in the presence of PLA at $50^{\circ} \mathrm{C}$ with the exception of the compost containing 50\% (w/w) PLA films, where the $\mathrm{pH}$ decreased from 6.5 to 3.1 after 4 months (data not shown) and coincided with PLA disintegration (figure 1). Previously, we showed that lactic acid release causing a large decrease in $\mathrm{pH}$ was only observed after loss in tensile strength indicating that release of lactic acid occurs in the final stages of polymer hydrolysis (Karamanlioglu et al. 2014). However, since compost is not a sterile system, released PLA oligomers and lactic acid will be utilized by microorganisms as a carbon source. This may explain why a decrease in $\mathrm{pH}$ was not observed with PLA films at concentrations lower than $50 \%$, as the released lactic acid may have been utilized by microbes present in the compost and insufficient to change the $\mathrm{pH}$ of the surrounding compost. In a study by Torres et al. (1996b), when PLA oligomers and lactic acid dimers were incubated with a fungus, Fusarium moniliforme, and a bacterium, Pseudomonas putida, separately, $\mathrm{pH}$ increase was observed in both cultures at $30^{\circ} \mathrm{C}$. In another study, the $\mathrm{pH}$ in an abiotic reactor and sterile water decreased in the presence of PLA at temperatures of $40^{\circ} \mathrm{C}-60^{\circ} \mathrm{C}$; however, $\mathrm{pH}$ increased in a biotic reactor under the same conditions due to utilization of released oligomers and lactic acid (Agarwal et al. 1998). In accordance with our study, Ghorpade et al. (2001) observed a decrease in $\mathrm{pH}$ when PLA was present in compost at a concentration of $30 \%(\mathrm{w} / \mathrm{w})$ at $52^{\circ} \mathrm{C}$ but not at a concentration of $10 \%(\mathrm{w} / \mathrm{w})$.

In order to determine if the presence of different concentrations of PLA influences the fungal community profile in compost, TRFLP profiles were compared by PCA (figure 2). PCA enables comparisons of complex data sets and is often used to analyze microbial TRFLP profiles (Dollhopf et al. 2001; Midgley, et al. 2007; Wang et al. 2004). At $50^{\circ} \mathrm{C}$, where disintegration of PLA was occurring, much greater variation in populations was evident by PCA. In the absence of PLA, the variation in the population was low compared to the variation in the presence of PLA and so the initial population clustered with the population in the absence of PLA after 2 and 4 months incubation. In the presence of PLA, the greatest divergence to the population compared to the absence of PLA was seen after 2 months but became more similar to the population in the absence of PLA after 4 months. The only exception was in the population containing $50 \%(\mathrm{w} / \mathrm{w})$ PLA film, which remained divergent and was the population in which the $\mathrm{pH}$ had significantly increased. This was also reflected in a lower number of detectable TRFs, diversity, and evenness in the compost community (table 1 ) as a result of the excess release of lactic acid.

Some TRFs appeared only in PLA containing compost and were not detected in compost without PLA (PLA unique TRFs; table 1). The percentage of PLA unique TRFs varied widely from 3 to $38 \%$ at $50^{\circ} \mathrm{C}$ suggesting a significant number of fungal species were under positive selection by the presence PLA, particularly at $50^{\circ} \mathrm{C}$ where hydrolysis was occurring. However, the total abundance of these PLA unique TRFs was never greater than $1 \%$ under any conditions suggesting they played a minimal role in PLA degradation and that selection for species already present at detectable levels in the population may be more important.

In order to obtain a more comprehensive view of the taxa affected by the presence of PLA, 454-pyrosequencing was employed to analyze the fungal community from compost in the presence and absence of $25 \%(w / w)$ PLA incubated at $50^{\circ} \mathrm{C}$ (figure 3). Compared to compost in the absence of PLA, the presence of PLA greatly affected the fungal composition of the compost with Thermomyces becoming the most dominant OTU. By contrast, in the absence of PLA, abundance of Thermomyces was very low as it was not identified in the initial compost community or after 4 months incubation and was only detected at low abundance $(0.03 \%)$ after 2 months incubation, whereas in the presence of PLA, relative abundance increased to 80 and $75 \%$ after 2 and 4 months, respectively. Previously, Thermomyces lanuginosus was found to be the dominant organism that could be cultured from the surface of PLA when incubated at $50^{\circ} \mathrm{C}$ in both compost and soil and was shown to have the ability to degrade high molecular weight PLA (Karamanlioglu et al. 2014). Apart from the Thermomyces sp., an uncultured Eurotiales in the same order was also identified from compost in the presence of 
PLA and was also not detected in the initial compost community suggesting that it may be another PLA degrader. The most abundant OTU in compost in the absence of PLA after 2 and 4 months incubation at $50^{\circ} \mathrm{C}$ was assigned to an unidentified clone (relative abundance of 79 and $97 \%$, respectively) and was present at a lower abundance in the presence of PLA (19 and $23 \%$ after 2 and 4 months incubation, respectively). The inability to identify environmental fungal clones is problematic and arises due to the deposition of internal transcribed spacer (ITS) sequences to international DNA databases without taxonomic annotations or containing errors in taxonomic assignments (Hawksworth 2004; Vilgalys 2003) and also it has been estimated that the vast majority of fungal species have not been cultured (Hawksworth, 2001).

In this study, it was shown that fungal diversity and community structure in compost is affected by the presence of PLA at $50^{\circ} \mathrm{C}$ with a marked shift in community structure after 2 months but returning toward the initial structure after 4 months indicating PLA causes a temporal shift in the community structure but returns too close to the original as the PLA is degraded. 454-Pyrosequencing of compost samples indicated that PLA caused a strong selection for a Thermomyces sp. after 2 months, whereas it was only a relatively minor component of the community in the absence of PLA. Thus, PLA entering composting systems could have a major effect on shifting the fungal community profile; further, studies are required to evaluate the impact of this perturbation on the composting process and subsequent compost quality.

\section{Acknowledgments}

The authors wish to thank Dr. A. Houlden for his expert advice.

\section{References}

Agrawal, C. M., D. Huang, J. P. Schmitz, and K. A. Athanasiou. 1997. Elevated temperature degradation of a 50:50 copolymer of PLA-PGA. Tissue Engineering 3:345-52.

Agarwal, C. M., K. W. Koelling, and J. J. Chalmers. 1998. Characterization of the degradation of polylactic acid polymer in a solid substrate environment. Biotechnology Progress 14:517-26.

Atlas, R. M., and R. Bartha. 1986. Microbial ecology: Fundamentals and applications. Menlo Park, CA: Benjamin-Cummings.
Auras, R. A., B. Harte, S. Selke, and R. Hernandez. 2003. Mechanical, physical, and barrier properties of poly(lactide) films. Journal of Plastic Film and Sheeting 19:123-35.

Bohlmann, G. M. 2005. General characteristics, processability, industrial applications and market evolution of biodegradable polymers. In: Handbook of Biodegradable Polymers, ed. C. Bastioli. Shrewsbury, UK: Rapra Technology Ltd.

Caporaso, J. G., J. Kuczynski, J. Stombaugh, K. Bittinger, F. D. Bushman, E. K. Costello, N. Fierer, A. G. Peña, J. K. Goodrich, J. I. Gordon, G. A. Huttley, S. T. Kelley, D. Knights, J. E. Koenig, R. E. Ley, C. A. Lozupone, D. McDonald, B. D. Muegge, M. Pirrung, J. Reeder, J. R. Sevinsky, P. J. Turnbaugh, W. A. Walters, J. Widmann, T. Yatsunenko, J. Zaneveld, and R. Knight. 2010. QIIME allows analysis of high-throughput community sequencing data. Nature Methods 7:335-36.

Dollhopf, S. L., S. A. Hashsham, and J. M. Tiedje. 2001. Interpreting 16S rDNA T-RFLP data: Application of self-organizing maps and principal component analysis to describe community dynamics and convergence. Microbial Ecology 42:495-505.

Dowd, S. E., T. R. Callaway, R. D. Wolcott, Y. Sun, Y. McKeehan, R. G. Hagevoort, and T. S. Edrington. 2008. Evaluation of the bacterial diversity in the feces of cattle using $16 \mathrm{~S}$ rDNA bacterial tag-encoded FLX amplicon pyrosequencing (bTEFAP). BMC Microbiology 8:125.

Drumright, R. E., P. R. Gruber, and D. E. Henton. 2000. Polylactic acid technology. Advanced Materials 12:1841-46.

Forster, J. 1995. Soil sampling, handling, storage and analysis. In: Methods in applied soil microbiology and biochemistry, ed. K. Alef, and P. Nanniperi. London, UK: Academic Press.

Garlotta, D. 2002. A literature review of poly (lactic acid). Journal of Polymers and the Environment 9:63-84.

Ghorpade, V. M., A. Gennadios, and M. A. Hanna. 2001. Laboratory composting of extruded poly(lactic acid) sheets. Bioresource Technology 76:57-61.

Hawksworth, D. L. 2001. The magnitude of fungal diversity: The 1.5 million species estimate revisited. Mycological Research 105:1422-32.

Hawksworth, D. L. 2004. "Misidentifications" in fungal DNA sequence databanks. New Phytologist 161:13-15.

Henton, D., P. Gruber, J. Lunt, and J. Randall. 2005. Polylactic acid technology. In: Natural Fibres, Biopolymers and Biocomposites, ed. A. K. Mohanty, M. Misra, and L. T. Drzal. Boca Raton, FL: CRC Press.

Itävaara, M., S. Karjomaa, and J.-F. Selin. 2002. Biodegradation of polylactide in aerobic and anaerobic thermophilic conditions. Chemosphere 46:879-85.

Kale, G., R. Auras, and S. P. Singh. 2007. Comparison of the degradability of poly (lactide) packages in composting and ambient exposure conditions. Packaging Technology and Science 20:49-70.

Karamanlioglu, M., A. Houlden, and G. D. Robson. 2014. Isolation and characterisation of fungal communities associated with degradation and growth on the surface of poly (lactic) acid (PLA) in soil and compost. International Biodeterioration and Biodegradation 95:301-10. 
Karamanlioglu, M., and G. D. Robson. 2013. The influence of biotic and abiotic factors on the rate of degradation of poly (lactic) acid (PLA) coupons buried in compost and soil. Polymer Degradation and Stability 98:2063-71.

Kawasaki, A., E. R. Watson, and M. A. Kertesz. 2012. Indirect effects of polycyclic aromatic hydrocarbon contamination on microbial communities in legume and grass rhizospheres. Plant and Soil 358:169-82.

Lim, L.-T., R. Auras, and M. Rubino. 2008. Processing technologies for poly(lactic acid). Progress in Polymer Science 33:820-52.

Lunt, J. 1998. Large-scale production, properties and commercial applications of polylactic acid polymers. Polymer Degradation and Stability 3910:145-52.

Midgley, D. J., J. A. Saleeba, M. I. Stewart, A. E. Simpson, and P. A. McGee. 2007. Molecular diversity of soil basidiomycete communities in northern-central New South Wales, Australia. Mycological Research 111:370-78.

Nova Institut. 2016. Renewable resources. www.nova-institut.de (accessed February 24, 2017).

Plastics Europe. 2016. The plastic portal. http://www.plasticseu rope.org/ (accessed February 24, 2017).

QIIME. 2016. QIIME fungal ITS analysis tutorial (an IPython Notebook): Open-reference OTU picking. http://qiime.org/ tutorials/fungal_its_analysis.html (accessed February 24, 2017).

Saadi, Z., A. Rasmont, G. Cesar, H. Bewa, and L. Benguigui. 2012. Fungal degradation of poly(l-lactide) in soil and in compost. Journal of Polymers and the Environment 20:273-82.

Sabev, H. A., S. Barratt, P. S. Handley, and G. D. Robson. 2006. Biodegradation and biodeterioration of man-made polymeric materials. In: Fungi in biogeochemical cycles, ed. G. M. Gadd. Cambridge, UK: Cambridge University Press.

Sangwan, P., C. Way, and D.-Y. Wu. 2009. New insight into biodegradation of polylactide (PLA)/clay nanocomposites using molecular ecological techniques. Macromolecular Bioscience 9:677-86.

Sangwan, P., and D.-Y. Wu. 2008. New insights into polylactide biodegradation from molecular ecological techniques. Macromolecular Bioscience 8:304-15.

Shah, A. A., H. Fariha, H. Abdul, and A. Safia. 2008. Biological degradation of plastics: a comprehensive review. Biotechnology Advances 26:246-265.
Shimao, M. 2001. Biodegradation of plastics. Current Opinion in Biotechnology 12:242-47.

Sivan, A. 2011. New perspectives in plastic biodegradation. Current Opinion in Biotechnology 22:422-26.

Smith, C. J., B. S. Danilowicz, A. K. Clear, F. J. Costello, B. Wilson, and W. G. Meijer. 2005. T-Align: A web-based tool for comparison of multiple terminal restriction fragment length polymorphism profiles. FEMS Microbiology Ecology 54:375-80.

T-align. 2016. T-align, a web based tool for comparison of multiple terminal restriction fragment length polymorphism profiles. http://inismor.ucd.ie/ talign/ (accessed February 24, 2017).

Torres, A., S. M. Li, S. Roussos, and M. Vert. 1996a. Screening of microorganisms for biodegradation of poly(lactic-acid) and lactic acid-containing polymers. Applied and Environmental Microbiology 62:2393-97.

Torres, A., S. M. Li, S. Roussos, and M. Vert. 1996b. Poly(lactic acid) degradation in soil or under controlled conditions. Journal of Applied Polymer Science 62:2295-302.

Vargas, B. L. F., B. A. Welt, P. Pullammanappallil, A. A. Teixeira, M. O. Balaban, and C. L. Beatty. 2009. Effect of electron beam treatments on degradation kinetics of polylactic acid (PLA) plastic waste under backyard composting conditions and science. Packaging Technology and Science 22:97106.

Vilgalys, R. 2003. Taxonomic misidentification in public DNA databases. New Phytologist 160:4-5.

Wang, M., S. Ahrné, M. Antonsson, and G. Molin. 2004. TRFLP combined with principal component analysis and 16S rRNA gene sequencing: An effective strategy for comparison of fecal microbiota in infants of different ages. Journal of Microbiological Methods 59:53-69.

Weir, N. A., F. L. Buchanan, J. F. Orr, D. F. Farrar, and G. R. Dickson. 2004. Degradation of poly-L-lactide. Part 2: Increased temperature accelerated degradation. Journal of Engineering in Medicine 218:321-30.

White, T. J., T. Bruns, and S. Lee. 1990. Amplification and direct sequencing of fungal ribosomal RNA genes for phylogenetics. In: PCR protocols: A guide to methods and applications, ed. M. Innis, D. Gelfand, J. Sninsky, and T. White. New York, NY: Academic Press.

Williams, D. F. 1982. Biodegradation of surgical polymers. Journal of Materials Science 17:1233-46. 